\title{
Fatal case of biliary cast syndrome in nontransplant patient
}

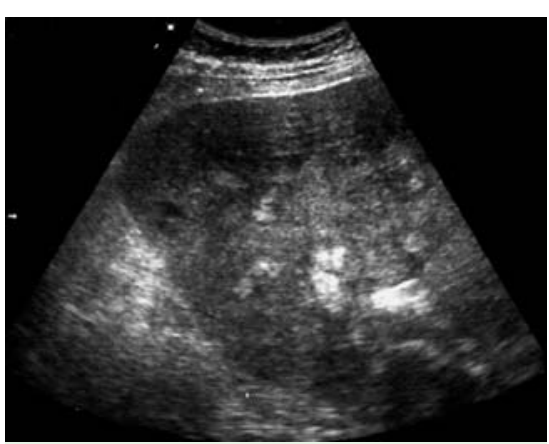

Fig. 1 Ultrasound of the liver.

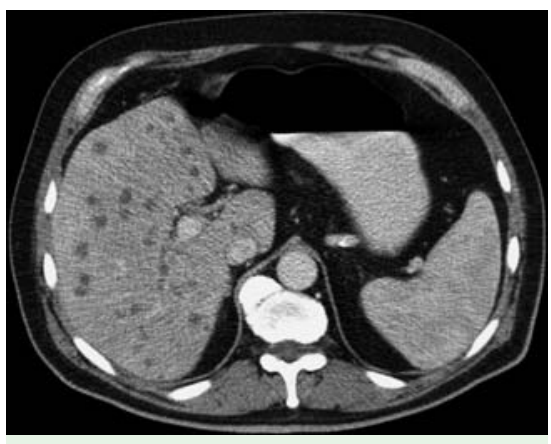

Fig. 2 Computed tomography.

A 69-year-old male, with no history of liver disease, was admitted after several days of low-grade fever, weakness, and jaundice, preceded by dyspepsia and diarrhea that occurred during recent holidays in North Africa. Laboratory tests revealed anemia (hemoglobin $7.7 \mathrm{~g} / \mathrm{dL}$ ), inflammation (C-reactive protein $148 \mathrm{mg} / \mathrm{L}$, white blood cells $16.6 \mathrm{~g} / \mathrm{L}$ ), and liver injury (alkaline phosphatase [ALP] $426 \mathrm{U} / \mathrm{L}$, gamma glutamyl transpeptidase [GGT] $160 \mathrm{U} / \mathrm{L}$, alanine aminotransferase [ALT] $90 \mathrm{U} / \mathrm{L}$, aspartate aminotransferase [AST] $114 \mathrm{U} / \mathrm{L}$, bilirubin rapidly rising to $22 \mathrm{mg} / \mathrm{dL}$ ). All possible etiologies of liver injury were excluded. Abdominal ultrasound and computed tomography revealed an enlarged liver with multiple focal lesions requiring differentiation between abscesses, metastases, or hamartomas ( $\bullet$ Fig. 1 and 2 ).

Endoscopic retrograde cholangiography showed irregular filling defects in extraand intrahepatic bile ducts, with cystic dilations of intrahepatic ducts, suggestive of microabscesses ( $\bullet$ Fig. 3). Outflow of pus with sludge was observed after

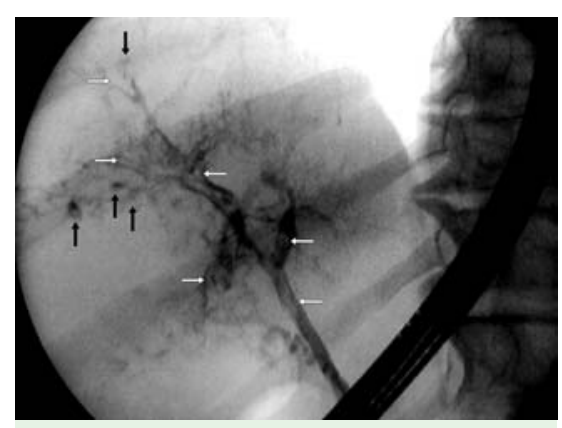

Fig. 3 Endoscopic retrograde cholangiography. Irregular filling defects (biliary casts) visible in both exta- and intrahepatic bile ducts (white arrows). Black arrows show cystic dilation of intrahepatic bile ducts presumed to be microabscesses.

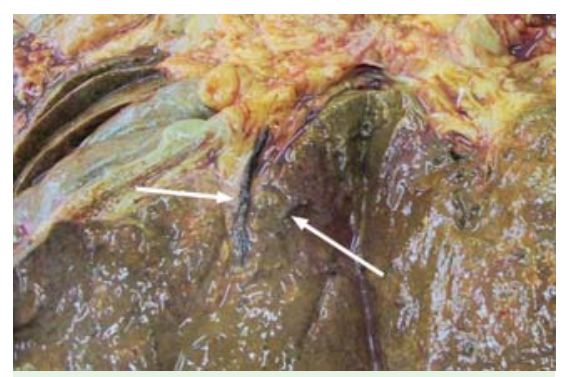

Fig. 4 Autopsy. Arrows show biliary casts protruding from bile ducts on the cross-section of the liver.

sphincterotomy. Escherichia coli was cultured from bile. Repeated attempts to remove the casts with a Dormia basket were unsuccessful.

The patient's condition deteriorated despite intensive care, and he died of progressive liver failure. On autopsy, the biliary tree, including small branches, was filled with cast replicating the ductal system ( $\bullet$ Fig. 4). Liver histopathology showed diffuse bile stasis in hepatocytes and portal fibrosis with mild inflammation.

Biliary cast syndrome is defined as the presence of casts (caused by retained lithogenic material) within the intra- and/ or extrahepatic bile ducts, causing obstruction and cholangitis, eventually complicated by multiple strictures, ductal dilation, and/or liver microabscesses. Biliary cast syndrome used to be a common fatal complication in the early years of liver transplantation, and was related to poor graft preparation [1,2]. When possible, biliary cast syndrome is treated endoscopically or surgically, including by liver transplantation [3-5].

There are only a few reports of biliary cast syndrome in nontransplant patients [35]. In the presented case the infection responsible for travellers' diarrhea and presumably cholangitis was the most probable triggering event in the development of casts. The involvement of small intrahepatic branches made endoscopic treatment ineffective and was responsible for liver failure.

Endoscopy_UCTN_Code_CCL_1AZ_2AJ

A. Dziurkowska-Marek ${ }^{1}$, M. Hartleb ${ }^{1}$,

T. A. Marek ${ }^{1}$, E. Nowakowska-Duława ${ }^{1}$,

R. Kaczor ${ }^{1}$, M. Ciupińska-Kajor ${ }^{2}$,

M. Kajor ${ }^{2}$

Department of Gastroenterology and Hepatology, Medical University of Silesia in Katowice, Katowice, Poland

Department of Pathology, Medical University of Silesia in Katowice, Katowice, Poland

\section{References}

1 Shah JN, Haigh WG, Lee SP et al. Biliary casts after orthotopic liver transplantation: clinical factors, treatment, biochemical analysis. Am J Gastroenterol 2003; 98: 1861 - 1867

2 Parry SD, Muiesan P. Cholangiopathy and the biliary cast syndrome. Eur J Gastroenterol Hepatol 2003; 15: $341-343$

3 D'Haens GR, Ruchim MA, Goldberg MJ et al. Massive intra-hepatic and extra-hepatic bile cast formation after cholecystectomy. Gastrointest Endosc 1993; 39: 579-581

4 Byrne MF, Chong HI, O'Donovan D et al. Idiopathic cholangiopathy in a biliary cast syndrome necessitating liver transplantation following head trauma. Eur J Gastroenterol Hepatol 2003; 15: 415-417

5 Gleeson FC, Czaja AJ, Baron TH. Successful endoscopic management of biliary cast syndrome in nonliver transplant patients. J Clin Gastroenterol 2008; 42: $752-755$

Bibliography

DOI $10.1055 / \mathrm{s}-0029-1215012$

Endoscopy 2009; 41: E256

(c) Georg Thieme Verlag KG Stuttgart · New York . ISSN 0013-726X

Corresponding author

\section{T. A. Marek, MD, PhD}

Department of Gastroenterology and Hepatology

Medical University of Silesia in Katowice

ul. Medyków 14

PL 40-752 Katowice

Poland

Fax: +48-32-2523119

tamarek@neostrada.pl 